\title{
Role of annealing temperature on Structural and Electric Transport properties of Pure $\mathrm{ZnO}$ nanoshapes
}

\author{
Anil Kaushik ${ }^{1}$, Dr S. K. Chaudhary ${ }^{2}$, Dr Ajay Kumar Mann ${ }^{3}$ \\ Research Scholar, Department of Physics, Baba Mastnath University, Asthal Bohar, Rohtak- 124021(Haryana) ${ }^{1}$ \\ HOD, Department of Physics, Baba Mastnath University, Asthal Bohar, Rohtak- 124021(Haryana) ${ }^{2}$ \\ Department of Physics, Pt. N. R. S. College, Rohtak- 124001(Haryana) ${ }^{3}$
}

\begin{abstract}
We used the co-precipitation method to create pure phase Zinc Oxide nanostructures in this study. X-ray diffraction was used to investigate the phase and scale of synthesised nanostructures (XRD). The ZnO sample calcined at $400{ }^{\circ} \mathrm{C}$ has a crystalline size of $36.1 \mathrm{~nm}$, an inter planner spacing of $2.7010 \AA$, and a volume of $71.62 \AA^{3}$. The morphological research was done using a scanning electron microscope (SEM). The IR peaks near around $510 \mathrm{~cm}^{-1}$ correspond to stretching of the Zn-O bonds, according to IR studies conducted with an FTIR spectrometer. A kaithely source metre was used to measure the current-voltage characteristics and resistivity of zinc oxide nanostructures. Impedance spectroscopy of synthesised samples was performed at room temperature using a galvinostat with an applied voltage of $120 \mathrm{mV}$ and a frequency range of $50 \mathrm{~Hz}$ to $5 \mathrm{MHz}$. For $\mathrm{ZnO}$ calcined at $400^{\circ} \mathrm{C}$, the grain boundary resistance is about $32 \mathrm{M} \Omega$ (at $310 \mathrm{~K}$ ).
\end{abstract}

Keywords: Zinc Oxide, X-RD, SEM, FTIR, AC Impedance Spectroscopy.

\section{INTRODUCTION}

The structural, morphological, mechanical, and optical properties of metal oxide semiconductors are excellent. Due to its large band gap semiconductor $\left(\mathrm{E}_{\mathrm{g}}=3.21-3.83 \mathrm{eV}\right)$ and numerous applications in sensor, catalysis, actuators, spintronics, and photovoltaic devices, $\mathrm{ZnO}$ has gotten a lot of attention in recent decades [1,2]. Various synthesis methods, such as sol-gel, co-perception, hydrothermal, and thermal evaporation, were used to synthesise $\mathrm{ZnO}$ nano structures. Among these techniques, the co-perception approach is most likely to synthesise $\mathrm{ZnO}$ nano structures in large enough amounts and at a low cost for industrial applications. Because of its diverse properties, $\mathrm{ZnO}$ is one of the most popular metal oxide semiconductors. $\mathrm{ZnO}$ is an II-VI semiconductor material with a wide variety of useful properties, making it a very promising material. The ionicity of $\mathrm{ZnO}$ lies somewhere between covalent and ionic semiconductor. Wurtzite (B4), zinc blende (B3), and rocksalt are the three types of crystal structures found in $\mathrm{ZnO}$. (B1). However, hexagonal wurtzite is the most stable phase in ambient conditions. The wurtzite structure of Zno is hexagonal (P63mc), with lattice parameters of $\mathrm{a}=\mathrm{b}=3.239$ and $\mathrm{c}=5.213$ [3]. Zn atoms are tetrahedrally coordinated to four oxygen atoms in $\mathrm{ZnO}$ nanostructures, and $\mathrm{Zn}$ 's 3d electrons hybridise with oxygen's 3p electrons [4]. Numerous pioneers have investigated the photo catalytic and optical properties of $\mathrm{ZnO}$ nanoparticles extensively in the literature; however, it is necessary to investigate the effect of annealing on phase, electric, and morphological properties of $\mathrm{ZnO}$ nanoparticles. As a result, we present a competent effort to recognise the effect of annealing on phase, electric, and morphological properties of $\mathrm{ZnO}$ nanoparticles. As a result, in this study, we used the co-perception method to synthesise $\mathrm{ZnO}$ nanostructures and investigated the effect of annealing temperatures on structural, optical, and dielectric properties.

\section{EXPERIMENTAL DETAILS:}

\subsection{Material}

Loba (India) uses zinc acetate dehydrate $(\mathrm{Zn}(\mathrm{CH} 3 \mathrm{COO}) 2$, sodium hydroxide $(\mathrm{NaOH})$, ethanol $(\mathrm{C} 2 \mathrm{H} 5 \mathrm{OH})$, and DI water as starting materials that do not need further purification.

\subsection{Synthesis Procedure}

The co-precipitation method was used to make $\mathrm{ZnO}$ nanoparticles. Initially, the starting materials for the emblematic 


\section{International Advanced Research Journal in Science, Engineering and Technology}

Vol. 8, Issue 8, August 2021

\section{DOI: $10.17148 / I A R J S E T .2021 .8803$}

synthesis process were taken in a stoichiometric ratio of zinc acetate dehydrate and sodium hydroxide. The precursors were then dissolved in ethanol and DI water, and the mixture was stirred for 2 hours at 80 degrees Celsius. After that, the solution was left to sit overnight before being washed with DI water and dried in an oven at $90^{\circ} \mathrm{C}$ for 12 hours. As a result, the powder was annealed for 2 hour at 400 degrees Celsius. After the full combustion process, the white powder was obtained.

\subsection{Characterizations}

X-ray diffraction (XRD) was used to describe and analyse the crystal phases of synthesised samples. Field Emission Scanning Electron Microscopy measurements were taken for morphological analyses of synthesised samples. The dc resistivity calculation was done with a Keithley 2400 source metre. The AC conductivity tests were carried out at room temperature with an AC impedance analyzer in a frequency range of up to $3 \mathrm{MHz}$.

\section{RESULTS AND DISCUSSIONS:}

\subsection{Structural Analysis:}

Figure 1 shows the XRD patterns of synthesised samples of $\mathrm{ZnO}$ nanostructures in the range of $2 \theta$ (diffraction angle) 20 to 80 . The diffraction peaks at $31.71,34.28,36.29,47.57,56.34,62.56,67.93,69.08,72.45,76.96$, and 81.52 correspond to hkl (100), (002), (101), (102), (110), (103), (200), and (112), (201) and (202), respectively. The JCPDS card number \#80-0075 matched all of the diffraction peaks. The Debye Scherer formula can be used to measure the average crystalline size (D) [2]:

$\mathrm{D}=\mathrm{K} \lambda / \beta \cos \theta$

Where $\mathrm{k}=0.91$ is the form factor, $1.54 \AA$ is the wavelength of $\mathrm{X}$-rays with $\mathrm{Cu} \mathrm{K}_{\alpha}$ radiation, $\beta$ is the full width at half maximum (FWHM), $\theta$ reflects the instruments broadening, and is the Bragg diffraction angle. Using the Bragg's law relationship, the interplanar spacing (dhkl) was calculated:

$2 \mathrm{~d} \sin \theta=\mathrm{n} \lambda$

Where ' $n$ ' denotes the diffraction order and $\theta$ denotes the diffraction angle.

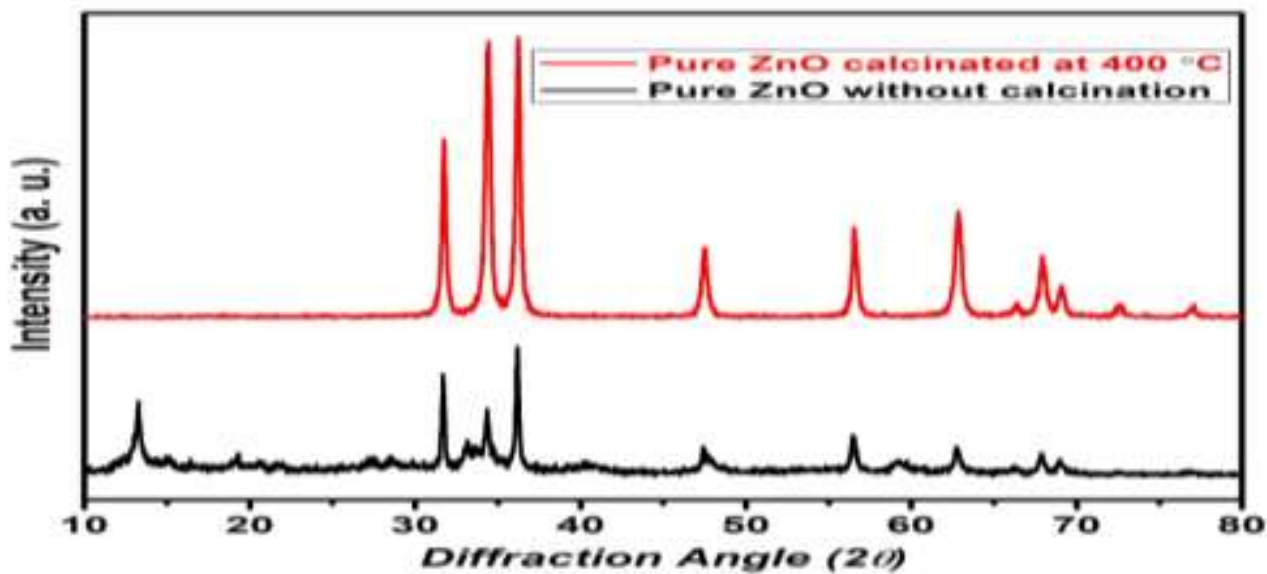

Figure 1. XRD pattern of pure $\mathrm{ZnO}$ (without calcinations and calcinated at $400{ }^{\circ} \mathrm{C}$ )

The lattice parameters and volume of the synthesized sample's unit cell were calculated using the following equations:

$$
\begin{aligned}
& \mathrm{a}=\mathrm{d}_{\mathrm{hkl}} * \sqrt{\mathrm{h}^{2}+\mathrm{k}^{2}+\mathrm{l}^{2}} \\
& \mathrm{~V}=0.88 * \mathrm{a}^{2} * \mathrm{c} \ldots \ldots \ldots \ldots
\end{aligned}
$$

The inter plane spacing is $\mathrm{d}_{\mathrm{hkl}}$, the miller indices of the planes are hkl, and the lattice parameters are a and c, which are tabulated in table 1. 
International Advanced Research Journal in Science, Engineering and Technology

Vol. 8, Issue 8, August 2021

DOI: $10.17148 /$ IARJSET.2021.8803

Table 1:

\begin{tabular}{|c|c|c|c|c|c|}
\hline \multirow[t]{2}{*}{ Samples } & \multirow[t]{2}{*}{$\begin{array}{l}\text { Crystalline Size } \\
(\mathbf{n m})\end{array}$} & \multirow{2}{*}{$\begin{array}{l}\text { Inter plane } \\
\text { spacing } \\
\left(\text { d }_{\text {hkl }}\right) \AA\end{array}$} & \multicolumn{2}{|c|}{$\underset{\AA}{\text { lattice parameters }}$} & \multirow[t]{2}{*}{$\begin{array}{l}\text { Unit Cell Volume (V) } \\
\AA^{3}\end{array}$} \\
\hline & & & $\mathbf{a}=\mathbf{b}$ & c & \\
\hline $\begin{array}{l}\mathrm{ZnO} \text { calcined at } \\
400^{\circ} \mathrm{C}\end{array}$ & 36.1 & 2.7010 & 3.7132 & 5.5861 & 71.62 \\
\hline
\end{tabular}

\subsection{Morphological Analysis:}

SEM (Scanning Electron Microscopy) was used to conduct the morphological tests, as shown in Figure 2. As the calcination temperature varied, the morphology of Zinc Oxide samples changed. The agglomerations of nano particles can be seen in the SEM micrograph of $\mathrm{ZnO}$ samples.
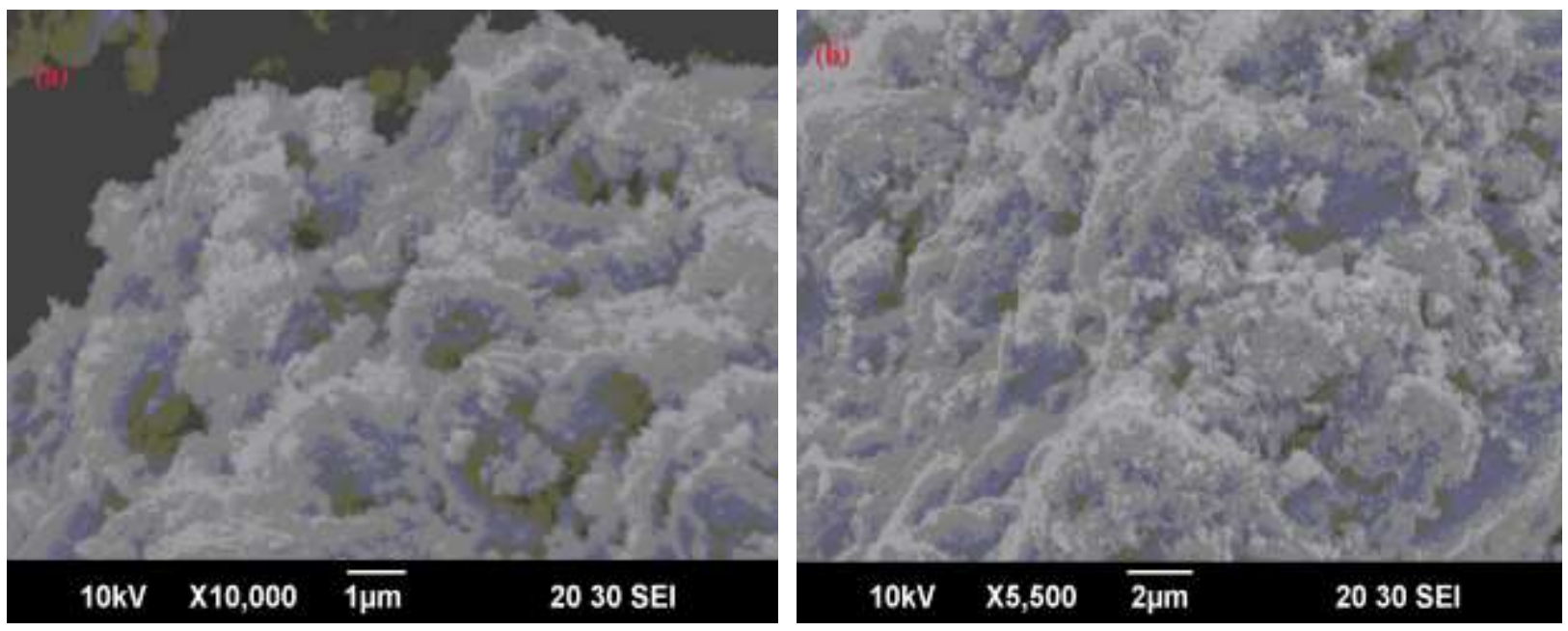

Figure 2 (a-b).: (a) $\mathrm{ZnO}$ micrograph without calcinations (b) $\mathrm{ZnO}$ micrograph for cacinated at $400{ }^{\circ} \mathrm{C}$

\subsection{FT-IR Studies:}

Figure 3 shows the FTIR spectrum of ZnO samples in the $500-3500 \mathrm{~cm}^{-1}$ range. $3365 \mathrm{~cm}^{-1}, 1554 \mathrm{~cm}^{-1}, 1376 \mathrm{~cm}^{-1}$, $1042 \mathrm{~cm}^{-1}, 934 \mathrm{~cm}^{-1}, 828 \mathrm{~cm}^{-1}, 669 \mathrm{~cm}^{-1}, 598 \mathrm{~cm}^{-1}$, and $510 \mathrm{~cm}^{-1}$ are the IR peaks in the samples. The vibration of the $\mathrm{C}-\mathrm{H}, \mathrm{C}=\mathrm{O}$, and $\mathrm{C}-\mathrm{O}$ bonds is represented by the IR peaks in the $710 \mathrm{~cm}^{-1}$ to $1690 \mathrm{~cm}^{-1}$ range. The peaks around 500 $\mathrm{cm}^{-1}$ lead to $\mathrm{Zn}-\mathrm{O}$ bond stretching $[4,5]$. The stretching vibrations of $\mathrm{O}-\mathrm{H}$ bonds and bending modes of absorbed water, as well as the presence of $\mathrm{O}=\mathrm{C}=\mathrm{O}$ bonds, correspond to the reaming peaks in the area $1690 \mathrm{~cm}^{-1}-3365 \mathrm{~cm}^{-1}$.

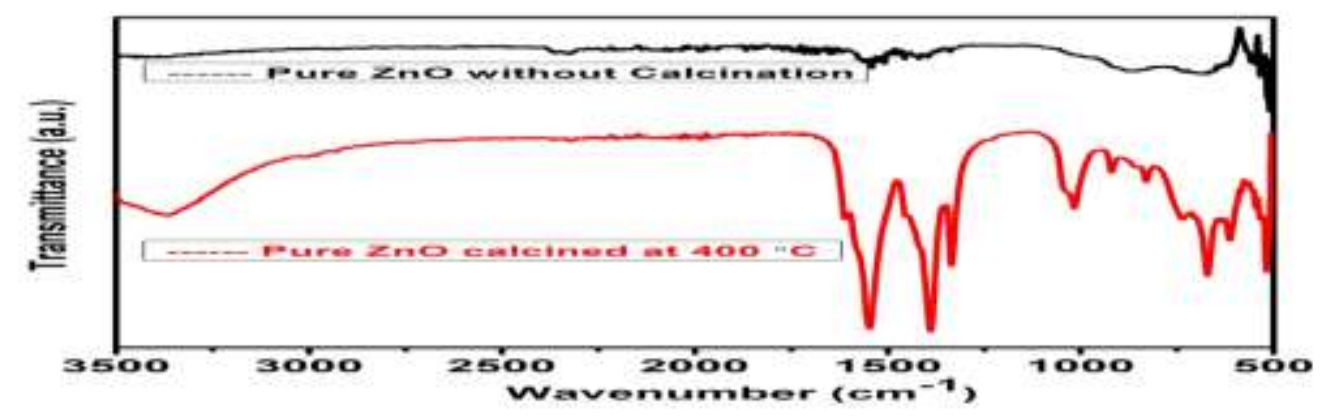

Figure 3. FTIR spectra of $\mathrm{ZnO}$ without calcinations and calcinated at $400{ }^{\circ} \mathrm{C}$ 


\section{DOI: 10.17148/IARJSET.2021.8803}

The IR peaks sharply appear in the range $510 \mathrm{~cm}^{-1}$ to $1545 \mathrm{~cm}^{-1}$ as the calcination temperature increases for $\mathrm{ZnO}$ sample, which is due to the presence of compressive stress on $\mathrm{ZnO}$ nanoparticles, increase in crystalline nature of $\mathrm{ZnO}$, and variation in morphology of $\mathrm{ZnO}$, as shown in XRD spectra and SEM micrograph of $400{ }^{\circ} \mathrm{C}$ calcined $\mathrm{ZnO}$ sample.

\subsection{Complex Impedance Studies:}

At room temperature, the electric activity of Zinc Oxide samples was investigated using complex impedance spectroscopy over a broad frequency spectrum. Figure 4 shows the nyquist plots of $\mathrm{ZnO}$ (calcined at $400^{\circ} \mathrm{C}$ ). An equation gives the complex impedance $(Z)$ :

$\mathrm{Z}=\mathrm{Z}^{\prime}-\mathrm{j} \mathrm{Z}^{\prime \prime}$

Where $\mathrm{Z}$ is the real part of complex impedance and $\mathrm{Z}$ is the imaginary part. The single semicircular curve formation in the cole-cole (Nyquist) plot confirms the presence of grains and a distinct relaxation mechanism in the synthesised $\mathrm{ZnO}$ samples.

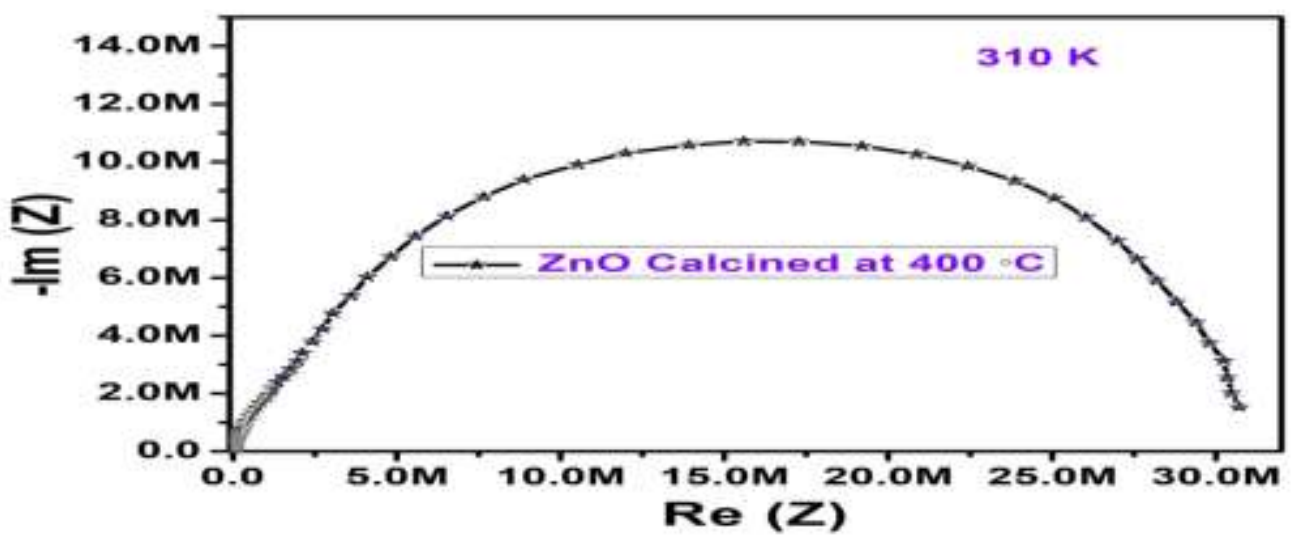

Figure 4. Nyquist plot of pure $\mathrm{ZnO}$ calcinated at $400{ }^{\circ} \mathrm{C}$

This spectroscopic technique is used to separate the true and imaginary parts of electronic parameters such as impedance $(\mathrm{Z})$, permittivity $(\varepsilon)$, dielectric loss $(\tan \delta)$, and admittance $(Y)$, among others. Furthermore, figure 5 depicts the variance of the real component $(\mathrm{Z})$ of complex impedance as a function of frequency at room temperature, and it is evident from the graph that the values of $\mathrm{Z}$ abruptly decrease as the frequency increases, owing to an increase in $\mathrm{AC}$ conductivity due to hopping conduction phenomena [6,7]. As a result, the actual component of impedance has a heavy frequency dependent behaviour in the low frequency range, which leads to higher resistivity and high grain boundary resistance values, while $Z$ has a frequency independent behaviour in the higher frequency range. In addition, figure 6 depicts the variance of $\mathrm{Z}$ as a function of frequency, which exhibits a similar pattern to $\mathrm{Z}$. The grain and grain boundary of the crystal system are split using Complex Impedance Spectroscopy (CIS), which corresponds to the low and high frequency dispersion field $[8,9]$.

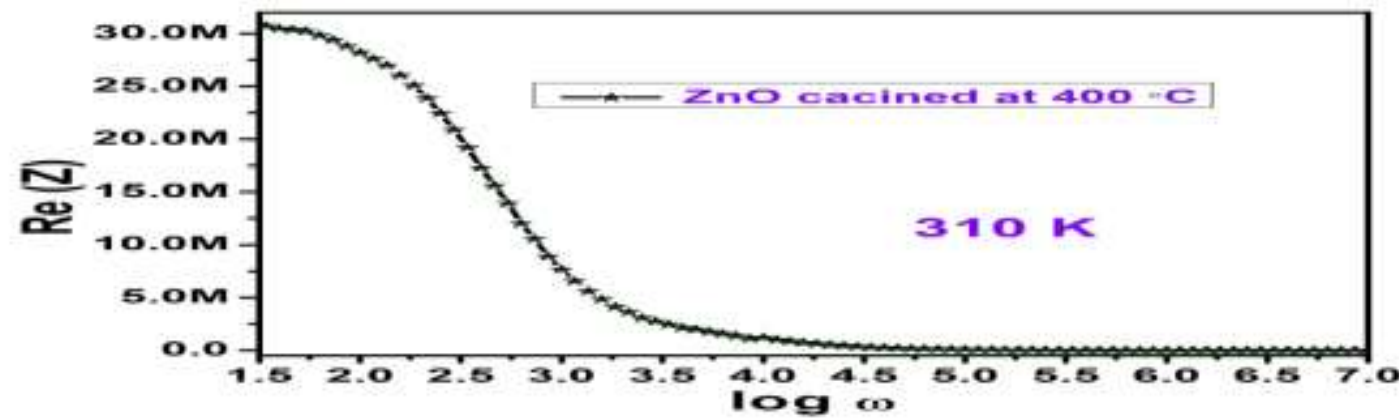

Figure 5: variation of Real part of complex Impedance with frequency for Pure $\mathrm{ZnO}$ calcinated at $400{ }^{\circ} \mathrm{C}$ 


\section{International Advanced Research Journal in Science, Engineering and Technology}

Vol. 8, Issue 8, August 2021

DOI: $10.17148 /$ IARJSET.2021.8803

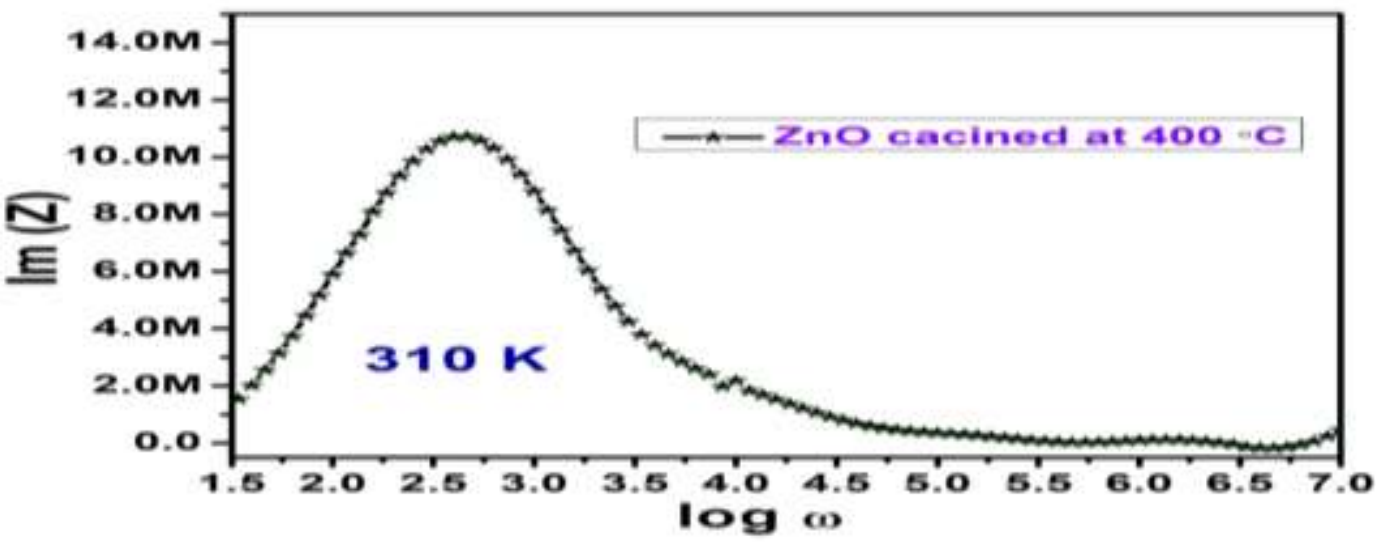

Figure 6: Variation of Imaginary part of complex impedance with frequency for Pure $\mathrm{ZnO}$ calcinated at $400{ }^{\circ} \mathrm{C}$

\section{CONCLUSION}

To investigate the effect of annealing on the synthesis process and properties, the Zinc Oxide (ZnO) samples were successfully synthesised using the co-perception technique at different annealing temperatures. The crystalline form, inter planner spacing, and volume of the $\mathrm{ZnO}$ sample calcined at $400{ }^{\circ} \mathrm{C}$ are $36.1 \mathrm{~nm}, 2.7010$, and 71.62 , respectively. Both $\mathrm{ZnO}$ samples have excellent structural, morphological, FTIR, and electronic transport properties. The vibration of the $\mathrm{C}-\mathrm{H}, \mathrm{C}=\mathrm{O}$, and $\mathrm{C}-\mathrm{O}$ bonds is represented by the FTIR peaks in the $705 \mathrm{~cm}-1$ to $1690 \mathrm{~cm}^{-1}$ range. The stretching of the $\mathrm{Zn}-\mathrm{O}$ bonds is defined by the peaks around $510 \mathrm{~cm}^{-1}$. The grain boundary resistance of $\mathrm{ZnO}$ calcined at $400{ }^{\circ} \mathrm{C}$ is around $32 \mathrm{M} \Omega($ at $310 \mathrm{~K}$ ). In the low frequency field, the real part of complex impedance has a strong frequency dependent behaviour, which correlates to higher resistivity and high grain boundary resistance values.

\section{AKNOWLEDGEMENT:}

The authors are grateful for the facilities provided by the Department of Physics at Baba Mastnath University, Asthal Bohar, Rohtak.

\section{REFERENCES:}

1. T. Sahoo et al., Synthesis and characterization of porous $\mathrm{ZnO}$ nanoparticles by hydrothermal treatment of as pure aqueous precursor, Materials Research Bulletin 46.4 (2011): 525-530.

2. S. B. Rana, et al., Synthesis and characterization of pure and doped $\mathrm{ZnO}$ nanoparticles, Journal of Optoelectronics and Advanced Materials 12.2 (2010): 257

3. D. Gao, et al., Room temperature ferromagnetism of pure ZnO nanoparticles, Journal of applied physics 105.11 (2009): 113928.

4. Divya R. "Effect of Azadirachta Indica in Metal Oxide Nanoparticles". International Research Journal on Advanced Science Hub, 2, 8 , 2020, 105-111. doi: 10.47392/irjash.2020.102

5. Meinathan S.; Mr. Kannakumar; Gnanavel P. "Experimental investigation on mechanical and FTIR analysis of novel bio materials reinforced epoxy composites". International Research Journal on Advanced Science Hub, 3, Special Issue ICIES-2021 4S, $1970,58-64$.

6. Rashmi S.K; H.S. Bhojya Naik; Jayadevappa H. "Optical and photocatalytic application of ZnFe2O4-SmFeO3 nanocomposites". International Research Journal on Advanced Science Hub, 2, 8, 2020, 123-130. doi: 10.47392/irjash.2020.105

7. Jakeer Husain; Rehana Anjum; Shivaraj G; Gavisiddayya Mathad; Deepa Pathar; Jaisheel Sagar; Bushara Anjum. "Electrical properties of polyaniline/Cadmium Oxide/ZnO Nanocomposites Thin Films". International Research Journal on Advanced Science Hub, 2, 8, 2020, 31-33. doi: 10.47392/irjash.2020.89

8. Jakeer Husain; Rehana Anjum; Narsappa Reddy; Jaisheel Sagar; Bushara Anjum. "AC Conductivity Studies on Polyaniline/Cobalt Oxide Nanocomposites Thin Films". International Research Journal on Advanced Science Hub, 2, 7, 2020, 41-43. doi: 10.47392/irjash.2020.62

9. Gajendiran R; K.Thirumalai raja. "Self-Healing of Wastewater Concrete Using Bacteria". International Research Journal on Advanced Science Hub, 2, 7, 2020, 82-89. doi: 10.47392/irjash.2020.69

10. B. Sharma et al., Synthesis and characterization of polyaniline-ZnO composite and its dielectric behavior, Synthetic metals $159.5-6$ (2009): 391-395.

11. P. I. Devi and K. Ramachandran, Dielectric studies on hybridised PVDF-ZnO nanocomposites, Journal of Experimental Nanoscience 6.3 (2011): 281-293.

12. R. Zamiri et al., Structural and dielectric properties of Al-doped ZnO nanostructures, Ceramics International 40.4 (2014): $6031-6036$.

13. H. Yadav et al., Eu-doped $\mathrm{ZnO}$ nanoparticles for dielectric, ferroelectric and piezoelectric applications, Journal of Alloys and Compounds 689 (2016): 333-341.

14. S. Sagadevan et al., Structural, dielectric and optical investigation of chemically synthesized Ag-doped ZnO nanoparticles composites, Journal of Sol-Gel Science and Technology 83.2 (2017): 394-404.

15. S. Goel et al., 2D porous nanosheets of Y-doped ZnO for dielectric and ferroelectric applications, Journal of Materials Science: Materials in Electronics 29.16 (2018): 13818-13832. 